\title{
Developmental capacity of mouse oocytes cryopreserved before and after maturation in vitro*
}

\author{
A. C. Schroeder†, A. K. Champlin $\ddagger$, L. E. Mobraaten and J. J. Eppig \\ The Jackson Laboratory, Bar Harbor, Maine 04609, USA
}

\begin{abstract}
Summary. The survival and developmental capacity of cumulus cell-enclosed oocytes frozen (1) at the germinal vesicle (GV) stage, after maturation in vitro with (2) and without (3) FSH, and (4) after gonadotrophin-stimulated ovulation were assessed. Survival, defined as the number of morphologically normal oocytes, after freeze-thaw at the GV stage (69\%), was lower than for oocytes frozen after ovulation $(84 \%)$, and after maturation in vitro with FSH $(88 \%)$ and without FSH $(81 \%)$. Treatment with DMSO without freezing had no effect on survival when compared with untreated controls except in immature GV-stage oocytes for which there was a slight reduction. After insemination in vitro, $9 \%$ of frozen-thawed GV-stage oocytes cleaved to two equal blastomeres, but none developed to blastocysts. Of oocytes matured in vitro before freezing, $17 \%$ cleaved to the 2-cell stage and $18 \%$ of these developed to blastocysts. When oocytes were matured in vitro in the presence of $\mathrm{FSH}$, however, the percentage cleaving to the 2-cell stage after freeze-thaw was improved to $55 \%$, and $77 \%$ of 2 -cell stage embryos developed to blastocysts. When ovulated cumulus cell-enclosed oocytes were frozen, $88 \%$ cleaved and $67 \%$ of the cleaved embryos developed to blastocysts. When 158 two-cell embryos resulting from oocytes matured in vitro with FSH were transferred to the oviducts of pseudopregnant foster mothers, 41 genetically marked live young were produced $(26 \%)$. These results demonstrate (1) that ova frozen after ovulation undergo normal preimplantation development with frequencies at or near those for unfrozen control oocytes, (2) FSH treatment of oocytes maturing in vitro greatly improves the capacity to cleave and develop to blastocysts after freeze-thaw and (3) oocytes frozen at the GV stage survive cryopreservation and undergo maturation in vitro but their developmetnal ability is severely impaired.
\end{abstract}

Keywords: freezing; oocyte maturation; oocyte preservation; fertilization; mouse

\section{Introduction}

The developmental capacity of mouse oocytes isolated at the germinal vesicle stage (GV) and matured in vitro is similar to that of superovulated eggs (Schroeder \& Eppig, 1984, 1989). Oocyte maturation in vitro with subsequent embryonic development has also been achieved in other species (Van Blerkom \& McGaughey, 1978; Shalgi et al., 1979; Staigmiller \& Moore, 1984; Goto et al., 1988; Sirard et al., 1988; Vanderhyden \& Armstrong, 1989). Improved species-specific maturation protocols may ultimately enable investigators to take advantage of the large number of immature oocytes contained in the mammalian ovary for increasing populations of valuable animals. To maximize the practical effectiveness of such protocols, however, techniques for long-term storage of oocytes similar to those currently employed for spermatozoa would be very useful.

\footnotetext{
*Reprint requests: to J. J. Eppig.

†Present address: Gettysburg College, Gettysburg, PA 17325, USA.

$\$$ Present address: Colby College, Waterville, ME 04901, USA.
} 
Since the first demonstration that ovulated mouse ova could be cryopreserved (Tsunoda et al., 1976; Parkening \& Chang, 1977; Whittingham, 1977), several investigators have attempted to freeze metaphase II oocytes with varied success (summarized in Friedler et al., 1988). There have been fewer reported attempts to freeze GV-stage oocytes (Whittingham, 1977; Heyman et al., 1986; Pellicer et al., 1988; Sathananthan et al., 1988) perhaps because, from the first description of oocyte maturation in vitro (Pincus \& Enzmann, 1935) until recently, attempts to achieve embryonic development of in-vitro matured oocytes have met with limited success. Attempts to freeze oocytes after maturation in vitro have not been reported. The study reported here evaluated the cryopreservation of cumulus cell-enclosed oocytes, frozen before and after maturation in vitro and after ovulation. Survival was compared with that of corresponding control groups treated with cryoprotectant and cooling but not freezing while the developmental capacity of each group was compared with corresponding untreated and unfrozen oocytes.

\section{Materials and Methods}

Animals. $(\mathrm{C} 57 \mathrm{BL} / 6 \mathrm{~J} \times \mathrm{SJL} / \mathrm{J}) \mathrm{F}_{1}$ mice were used for all experiments. Immature GV-stage, cumulus cell-enclosed oocytes were obtained from juvenile 22-24-day-old mice 44-52 h after administration of 5 i.u. PMSG (Diosynth, Chicago, IL 60618, USA). Ovulated oocytes were retrieved from the oviducts of PMSG-primed mice 14-15 h after administration of 5 i.u. hCG. Spermatozoa for fertilization in vitro were obtained from 4-month-old males housed individually from the time of weaning.

Oocyte maturation, fertilization, embryonic development in vitro, and embryo transfer. The oocyte maturation medium was Eagle's Minimum Essential Medium (MEM), supplemented with $5 \%$ fetal bovine serum (FBS; Hyclone, Logan, UT 8432I, USA), 0.23 mm-pyruvic acid, 0.01\% phenol red (Difco, PO Box 1058, Detroit, MI 48232, USA), $50 \mathrm{mg}$ streptomycin sulphate $/ 175 \mathrm{mg}$ penicillin $\mathrm{G}$ potassium salt/l and Earle's salts (components purchased from Sigma Chemical Co., PO Box 14508, St Louis, MO 63178, USA). Media were made up with water collected from a spring in Franklin, Maine, USA, and distilled once. FSH (ovine FSH-17), kindly provided by the pituitary hormone distribution program (NIADDK), was used at a concentration of $1 \mu \mathrm{g} / \mathrm{ml}$. Medium for fertilization and embryo culture was Whitten's medium (Whitten, 1971) containing $3 \mathrm{mg}$ bovine serum albumin/ml (BSA crystallized; ICN, PO Box 1200, Lisle, IL 60532, USA). Oocyte maturation, fertilization, and embryo culture were carried out as described previously (Schroeder \& Eppig, 1984). Genetically marked 2-cell stage embryos were transferred to the oviduct ampullae of Day-1 pseudopregnant foster mothers with the aid of a No. 8 acupuncture needle (Pease $e t$ al., 1989).

Oocyte freezing and thawing. Four different groups of cumulus cell-enclosed oocytes were subjected to a slowfreeze/slow-thaw technique originally devised for mouse embryos by Whittingham et al. (1972) and currently used in the frozen embryo repository at the Jackson Laboratory (Mobraatten, 1986). The groups were (1) GV-stage oocytes isolated in 50 $\mu \mathrm{M}$-1-isobutyl-3-methylxanthine (IBMX; Aldrich, PO Box 355, Milwaukee, WI 53201, USA) which reversibly maintains meiotic arrest, (2) oocytes matured in vitro for $15-16 \mathrm{~h}$, (3) oocytes matured in vitro for $15-16 \mathrm{~h}$ in medium containing $1 \mu \mathrm{g} \mathrm{FSH} / \mathrm{ml}$, and (4) ovulated oocytes. Before freezing, the cumulus cell-enclosed oocytes were washed three times in Dulbecco's phosphate-buffered saline (PBS) containing 0.01\% phenol red and 5\% FBS to prevent zona hardening which inhibits fertilization (Downs et al., 1986a). Groups of 25-50 oocytes in $0.1 \mathrm{ml}$ PBS + FBS were placed into a round-bottomed freezing vial (Nunclon; Wesco, Billerica, MA 01221, USA) on ice. After $15 \mathrm{~min}$, freshly prepared PBS $(0.1 \mathrm{ml})$ containing $2 \mathrm{M}$-dimethyl sulphoxide (DMSO; Aldrich) was added and the tubes were equilibrated for $30 \mathrm{~min}$ on ice. Ice nucleation (seeding) was induced in a salted ice bath at $-6^{\circ} \mathrm{C}$. The tubes were then cooled to $-80^{\circ} \mathrm{C}$ in a freezing apparatus (Cryomed, Mt Clemens, MI 48045, USA) at a rate of $0.5^{\circ} \mathrm{C} / \mathrm{min}$ then immersed in liquid nitrogen at $-196^{\circ} \mathrm{C}$.

Oocytes were stored for periods ranging from 2 days to 2 months. For thawing, tubes were removed from liquid nitrogen and held in nitrogen vapour at $-101^{\circ} \mathrm{C}$ for $10 \mathrm{~min}$ then transferred to the thawing apparatus (Planer, Sunbury-on-Thames, Middlesex TW16 7HD, UK) and warmed at $8^{\circ} \mathrm{C} / \mathrm{min}$ to $+12^{\circ} \mathrm{C}$. The contents of the tubes were diluted by 10 sequential additions of $0 \cdot 1 \mathrm{ml}$ PBS + FBS at 1 -min intervals. The contents of the tube were then quickly transferred to $1.5 \mathrm{ml}$ PBS + FBS in a $35 \times 10 \mathrm{~mm}$ Corning tissue-culture dish, washed twice in PBS + FBS and twice in MEM or Whitten's medium. Percentage survival was assessed after $1 \mathrm{~h}$ in culture by determining the numbers of oocytes that appeared normal and those that were pycnotic. The effects of DMSO and cooling without freezing were determined for some of the oocytes in each group. The developmental capacity of frozen-thawed oocytes was determined in a second experiment. Surviving oocytes were prepared for fertilization or maturation in vitro, immediately upon thawing. Unfrozen, non-cooled and non-DMSO treated oocytes from each of the four groups served as controls.

Statistics. Data from 4 separate experiments were pooled and the results subjected to $\chi^{2}$ analysis with Yates' correction. 


\section{Results}

Table 1 compares the survival frequencies of 4 groups of oocytes $1 \mathrm{~h}$ after thawing, and control groups treated with DMSO and cooled but not frozen. Nearly 100\% of the control DMSO-treated unfrozen oocytes in each group survived except for immature germinal vesicle-stage oocytes $(88 \%)$. Immature GV-stage oocytes frozen immediately after their isolation from antral follicles had a lower survival frequency $(69 \%)$ than oocytes frozen after maturation in vitro with or without FSH or frozen ovulated oocytes, all of which had approximately the same survival frequency. After maturation in vitro without FSH and freeze-thaw, $81 \%$ of ova appeared morphologically normal which was significantly lower than for unfrozen DMSO treated controls. The remainder of the ova showed a darkened central area and were assumed to be degenerate. The cumulus cells of ova matured in vitro remain compacted around the ova. After freeze-thaw, however, in contrast to DMSO-treated controls, many of the cumulus cells appeared pycnotic and only a few remained attached to the oocyte. Cumulus cell-enclosed ova frozen after maturation in medium containing FSH, which stimulates the synthesis of hyaluronic acid and cumulus expansion (Eppig, 1979), had a survival frequency of $88 \%$. The cumulus cells in this group appeared identical to those of DMSO-treated controls, and the gel-like hyaluronic acid matrix of the expanded complexes remained intact (Fig. 1). For the ovulated cumulus cell-enclosed ova, which were dissected from the clutch into individual cumulus cell-enclosed eggs before freezing, $84 \%$ survived and they appeared identical to DMSO-treated controls and to the group matured in vitro with FSH and then frozen-thawed.

Table 1. Survival* of cumulus cell-enclosed oocytes frozen before and after maturation in vitro and after gonadotrophin-stimulated ovulation

\begin{tabular}{|c|c|c|c|c|}
\hline Group & Treatment & $\begin{array}{l}\text { No. of } \\
\text { oocytes }\end{array}$ & $\begin{array}{l}\text { No. recovered } \\
(\%)\end{array}$ & $\begin{array}{c}\text { No. morphologically } \\
\text { normal }(\%)\end{array}$ \\
\hline Germinal vesicle stage $\uparrow$ & $\begin{array}{c}\text { Frozen } \\
\text { DMSO-cooled } \ddagger\end{array}$ & $\begin{array}{l}300 \\
342\end{array}$ & $\begin{array}{ll}282 & (94) \\
339 & (99)\end{array}$ & $\begin{array}{l}194(69)^{\mathrm{a}} \\
300(88)\end{array}$ \\
\hline Matured in vitro & $\begin{array}{c}\text { Frozen } \\
\text { DMSO cooled }\end{array}$ & $\begin{array}{l}296 \\
201\end{array}$ & $\begin{array}{l}284(96) \\
201(100)\end{array}$ & $\begin{array}{l}230(81)^{\mathbf{b}} \\
199(99)\end{array}$ \\
\hline $\begin{array}{l}\text { Matured in vitro }+\mathrm{FSH} \\
\quad(\mathrm{I} \mu \mathrm{g} / \mathrm{ml})\end{array}$ & $\begin{array}{c}\text { Frozen } \\
\text { DMSO-cooled }\end{array}$ & $\begin{array}{l}270 \\
139\end{array}$ & $\begin{array}{l}270(100) \\
139(100)\end{array}$ & $\begin{array}{l}237(88)^{\mathrm{c}} \\
137(99)\end{array}$ \\
\hline Ovulated & $\begin{array}{c}\text { Frozen } \\
\text { DMSO-cooled }\end{array}$ & $\begin{array}{l}237 \\
110\end{array}$ & $\begin{array}{l}233(98) \\
110(100)\end{array}$ & $\begin{array}{l}196(84)^{b c} \\
107(97)\end{array}$ \\
\hline
\end{tabular}

Values represent data pooled from 4 experiments. Values with different letters are significantly different, $P<0.05$ at least. DMSO treatment groups are significantly different from their corresponding frozen-thawed group, $P<0.01$. *Morphologically normal $1 \mathrm{~h}$ after thawing.

$\uparrow$ Cumulus cell-enclosed oocytes were collected in medium containing $50 \mu \mathrm{M}$-IBMX to maintain meiotic arrest during processing for freezing.

$¥$ † umulus cell-enclosed oocytes were subjected to DMSO treatment and cooling as described in 'Materials and Methods' then warmed and examined after $1 \mathrm{~h}$ for survival.

Table 2 compares the percentage of successful development to the 2-cell and blastocyst stages of surviving frozen-thawed ova from the four groups and also compares each group with corresponding unfrozen non-DMSO-treated control ova. Although the oocytes that survived freezing at the GV stage underwent maturation in vitro as indicated by germinal vesicle breakdown (GVB) $(>95 \%)$ and polar body formation $(>90 \%)$, only a few developed to the 2-cell stage and none of the embryos developed to blastocysts. Of surviving ova frozen after maturation in vitro without FSH, a greater percentage developed to the 2-cell stage after insemination and $18 \%$ of these 

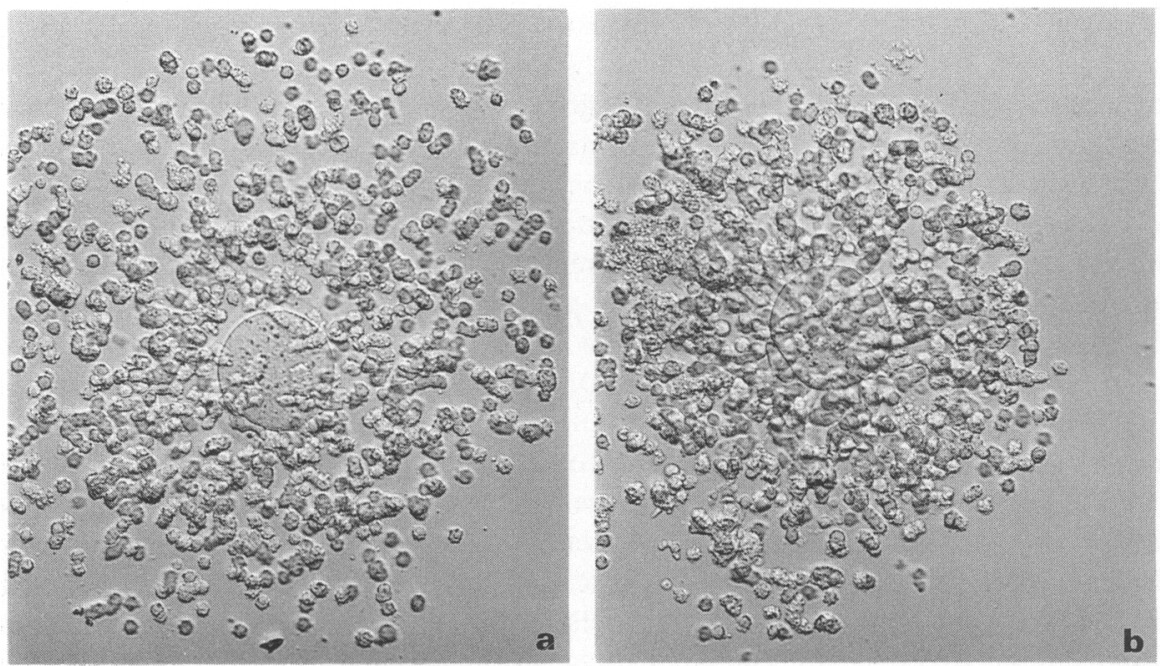

Fig. 1. Cumulus cell-enclosed ova (a) after maturation in vitro in medium containing FSH,

(b) after maturation in vitro in medium containing FSH followed by freeze-thaw. $\times 185$.

developed to blastocysts, but the values were significantly below those for corresponding unfrozen in-vitro matured controls.

Ova frozen after maturation in medium containing FSH developed to the 2-cell stage and blastocysts at significantly higher frequencies than those which were matured without FSH then frozen. Although a significantly greater percentage of the corresponding unfrozen control ova developed to the 2-cell stage, there was no difference in blastocyst development. In an experiment not shown in Table 2, when oocytes matured in vitro with FSH were subjected to cooling and DMSO treatment but not freezing, $72 \%$ developed to the 2-cell stage $(n=212)$ which was significantly lower than in the corresponding untreated group $(89 \% ; n=158)$, but significantly above that for frozen-thawed oocytes $(53 \% ; n=144)$.

Table 2. Developmental capacity of cumulus cell-enclosed oocytes frozen before and after maturation in vitro and after gonadotrophin-stimulated ovulation

\begin{tabular}{lcccc}
\hline \multicolumn{1}{c}{ Group } & $\begin{array}{c}\text { No. of } \\
\text { ova } \\
\text { inseminated }\end{array}$ & $\begin{array}{c}\text { No. of } \\
\text { 2-cell stage } \\
\text { embryos }(\%)\end{array}$ & $\begin{array}{c}\text { No. of embryos } \\
\text { continued in } \\
\text { culture }\end{array}$ & $\begin{array}{c}\text { No. of } \\
\text { blastocysts (\%) from } \\
\text { 2-cell stage embryos }\end{array}$ \\
\hline Germinal vesicle stage (frozen)* & 263 & $24(9)^{\mathrm{a}}$ & 24 & $0(0)^{\mathrm{a}}$ \\
In-vitro matured (frozen) & 170 & $29(17)^{\mathrm{b}}$ & 23 & $4(17)^{\mathrm{a}}$ \\
In-vitro matured (not frozen) & 192 & $123(64)^{\mathrm{c}}$ & 120 & $77(64)^{\mathrm{b}}$ \\
In-vitro matured + FSH (frozen) $\dagger$ & 487 & $267(55)^{\mathrm{d}}$ & 109 & $84(77)^{\mathrm{c}}$ \\
In-vitro matured + FSH (not frozen) & 211 & $175(83)^{\mathrm{e}}$ & 175 & $123(70)^{\mathrm{bc}}$ \\
Ovulated (frozen) & 147 & $129(88)^{\mathrm{e}}$ & 111 & $74(67)^{\mathrm{c}}$ \\
Ovulated (not frozen) & 240 & $192(80)^{\mathrm{e}}$ & 158 & $122(77)^{\mathrm{c}}$ \\
\hline
\end{tabular}

Values represent data pooled from 4 experiments. Values in a column with different letters are significantly different, $P<0.05$, at least.

${ }^{*} \mathrm{GV}$-stage, cumulus cell-enclosed oocytes were isolated in medium containing IBMX (50 $\left.\mu \mathrm{M}\right)$ to maintain meiotic arrest during processing for freezing. Oocytes were matured in vitro after thawing. Control is the same as in-vitro matured (not frozen).

$\dagger$ Transfer of 1582 -cell stage embryos from this group produced 41 live young $(26 \%)$ 
There was no difference between the frequencies of ovulated frozen-thawed ova and control ova which developed to the 2-cell stage, but the development of ovulated ova to the 2-cell stage was significantly better than for oocytes frozen after maturation in vitro with FSH. There was, however, no difference in the percentage that reached the blastocyst stage for these two groups when compared with their respective control group or with each other.

When 158 two-cell stage embryos, derived from oocytes frozen after maturation in vitro with FSH, were transferred to the oviducts of pseudopregnant foster mothers, 41 genetically marked live young were born $(26 \%)$.

\section{Discussion}

This study reports the successful cryopreservation of mouse ova after maturation in vitro. The survival and developmental capacity of four groups were compared: (1) immature GV stage oocytes which were frozen-thawed then matured in vitro, oocytes matured in vitro in the presence (2) and absence (3) of FSH and then frozen-thawed, and (4) ovulated eggs which were frozen-thawed. When cumulus cell-enclosed oocytes were matured in vitro then frozen-thawed, percentages of surviving oocytes were significantly higher than for oocytes frozen-thawed at the GV stage then matured in vitro and equivalent to survival of frozen-thawed ovulated oocytes. Forty-one genetically marked live young $(26 \%)$ were produced from transferred embryos that resulted from in-vitro fertilization of ova frozen-thawed after maturation in vitro with FSH.

Survival of immature oocytes frozen at the GV stage was improved over that reported earlier for the mouse (Whittingham, 1977; Sathananthan et al., 1988). This may be the result of inclusion of IBMX in the isolation medium to inhibit GVB reversibly during the processing steps for freezing. GVB is initiated immediately upon liberation from the follicular environment and is completed in virtually all cumulus cell-enclosed oocytes after $75 \mathrm{~min}$. This may be a particularly sensitive period since there is movement and rearrangement of various organelles and microtubules within the ooplasm (Calarco et al., 1972; Wassarman \& Fujiwara, 1978; Van Blerkom \& Runner, 1984; Albertini, 1987; Alexandre \& Mulnard, 1988). Spindle microtubule reorganization is particularly sensitive to cold (Magistrini \& Szollosi, 1980; Johnson \& Pickering, 1987; Pickering \& Johnson, 1987; Sathananthan et al., 1988). Maintenance of meiotic arrest with IBMX or other meiosis-arresting agents followed by maturation in vitro resulted in normal frequencies of development (Downs et al., 1986b). In the present study, more than $90 \%$ of immature GV-stage frozen-thawed oocytes underwent GVB and extrusion of a polar body. This suggests that the microtubular spindle apparatus was functional. The kinetics of GVB were not assessed in this study, but Pellicer et al. (1988) have shown that freezing slows subsequent GVB in rat oocytes. In agreement with previous reports (Whittingham, 1977; Sathananthan et al., 1988), embryonic development of immature frozen oocytes after thawing, maturation in vitro, and insemination in vitro, was deficient compared with that in unfrozen controls. This could be the result of damaged cumulus cells being unable to support maturation fully and/or possible damage to microtubule organization which is reflected at the first mitotic division. When oocytes matured in the presence of FSH were subjected to DMSO treatment and cooling but not freezing, their developmental capacity was better than for corresponding frozen oocytes but below that of untreated controls. This suggests a possible additive effect of cooling-DMSO treatment with freezing on the developmental ability of this group.

When ovulated metaphase II cumulus cell-enclosed oocytes were frozen-thawed, subsequent embryonic development was equivalent to that of unfrozen controls. The improved frequencies reported here for ovulated oocytes when compared with previous studies for the mouse and other species (summarized by Friedler et al., 1988) may be strain and species dependent. Alternatively, the ovulated clutches containing 20-40 oocytes were carefully dissected into individual cumulus cell-enclosed oocytes with the aid of sterile needles, and groups of 25-50 oocytes were then

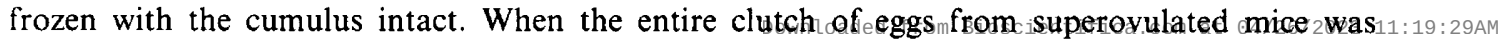


frozen-thawed, survival was markedly lower (data not shown). Improved success in freezing ovulated oocytes may also be due to inclusion of serum in the solutions for the freeze-thaw processing steps up to the time of insemination when the ova were quickly washed and placed into Whitten's medium containing BSA. Serum has been shown to prevent hardening of the zona pellucida of oocytes maturing in vitro and metaphase II oocytes (Downs et al., 1986a). Carroll et al. (1989) observed only a $46 \%$ cleavage rate for ovulated oocytes processed in serum containing PB 1 medium (Whittingham, 1974), but the oocytes were treated with hyaluronidase before processing to remove the cumulus cells and there was a prolonged period after thawing before insemination during which the ova were in PB1 that did not contain serum.

Attempts to freeze-thaw ovulated eggs, in-vitro matured oocytes, or GV-stage oocytes after they were first denuded of their cumulus cells resulted in lower survival when compared with cumulus cell-enclosed oocytes (data not shown). These results for immature oocytes agree with those of Pellicer et al. (1988), who found that the more layers of cumulus cells, the higher the survival in frozen-thawed rat oocytes. However, Whittingham (1977) found no difference in the survival or ability to cleave to the 2-cell stage for ovulated ova frozen-thawed with or without cumulus.

Survival of oocytes frozen-thawed after maturation in vitro in the presence or absence of FSH was about equal but the developmental capacity of those matured with FSH was significantly better. These findings confirm previous results (Downs et al., 1986b), showing that inclusion of FSH in the maturation medium significantly improves the developmental potential of oocytes matured in vitro. The percentage of 2-cell stage embryos, derived from ova frozen-thawed after maturation in vitro with FSH, that developed to blastocysts was the same as for unfrozen controls as well as frozen and unfrozen ovulated oocytes. The improved survival and developmental capacity of maturing oocytes treated with FSH compared to those which were matured untreated may be due to FSH-stimulated cumulus expansion. Frozen-thawed FSH-treated oocyte-cumulus cell complexes as well as ovulated frozen-thawed complexes appeared morphologically identical to unfrozen FSH-treated controls and ovulated control oocytes. The gel-like hyaluronic acid matrix appeared unperturbed by freezing and may provide a cryoprotective effect. Moreover, the cumulus cells within the expanded hyaluronic acid matrix did not appear pycnotic, in contrast to the cumulus cells from the groups in which the cumulus cell-enclosed oocytes were frozen without expansion. In these groups, many of the cumulus cells were pycnotic after freeze-thaw, and the oocyte was often denuded of remaining cells as a result of the manipulations for maturation or fertilization. Oocytes denuded of cumulus cells before maturation in vitro exhibit a lower developmental capacity than do cumulus cell-enclosed oocytes (Schroeder \& Eppig, 1984).

The experiments reported here were performed under controlled laboratory conditions with cumulus cell-enclosed oocytes isolated from PMSG-primed juvenile mice. Nevertheless, administration of exogenous gonadotrophins is not necessary to recover developmentally competent GV-stage oocytes (Schroeder \& Eppig, 1989) and live young were produced from in-vitro matured oocytes isolated from unprimed adult cyclic females at all stages of the oestrous cycle. In the present study, embryonic development was obtained after in-vitro matured oocytes isolated from such unprimed mice were frozen-thawed (data not shown).

The study reported here suggests that oocyte banking of ovulated and/or in-vitro matured oocytes is now possible for the mouse. The potential advantages of gamete banking in mammals are many, including the easy establishment of genetic combinations when male and female gametes in the desired combination are not simultaneously available. The practical advantages of oocyte development in vitro include the recovery of a greater number of developmentally competent oocytes from an ovary than will ever be ovulated. Also, maturation in vitro could serve to rescue mice that are otherwise reproductively impaired (Schroeder \& Eppig, 1989). Thus refined speciesspecific techniques of oocyte maturation in vitro coupled with ova freezing could ultimately increase the repertoire of current reproductive technology in other mammals, particularly valuable

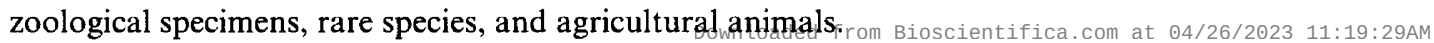


This research was supported by the National Cooperative Program on Non-Human in vitro Fertilization and Preimplantation Development and was funded by the National Institute of Child Health and Human Development, NIH, through cooperative agreement HD 21970. We thank Marilyn O'Brien, Elizabeth Drake and Sally Chamberlin for dedicated technical assistance.

\section{References}

Albertini, D.F. (1987) Cytoplasmic reorganization during the resumption of meiosis in cultured rat oocytes. Devl Biol. 120, 121-131.

Alexandre, H. \& Mulnard, J. (1988) Time-lapse cinematography study of the germinal vesicle behavior in mouse primary oocytes treated with activators of protein kinases A and C. Gamete Res. 21, 359-365.

Calarco, P.G., Donahue, R.P. \& Szollosi, D. (1972) Germinal vesicle breakdown in the mouse oocyte. $J$. Cell Sci. 10, 369-385.

Carroll, J., Warnes, G.M. \& Matthews, C.D. (1989) Increase in digyny explains polyploidy after in-vitro fertilization of frozen-thawed mouse oocytes. $J$. Reprod. Fert. 85, $489-494$.

Downs, S.M., Schroeder, A.C. \& Eppig, J.J. (1986a) Serum maintains the fertilizability of mouse oocytes matured in vitro by preventing the hardening of the zona pellucida. Gamete Res. 15, 115-122.

Downs, S.M., Schroeder, A.C. \& Eppig, J.J. (1986b) The developmental capacity of mouse oocytes following maintenance of meiotic arrest in vitro. Gamete Res. $15,305-316$.

Eppig, J.J. (1979) FSH stimulates hyaluronic acid synthesis by oocyte-cumulus cell complexes from mouse preovulatory follices. Nature, Lond. 281, 483-484.

Friedler, S., Giudice, L.C. \& Lamb, E.J. (1988) Cryopreservation of embryos and ova. Fert. Steril. 49, $743-764$.

Heyman, Y., Smorag, A., Katska, L. \& Vincent, C. (1986) Influences of carbohydrates, cooling and rapid freezing on viability of bovine non-maturated oocytes or 1-cell fertilized eggs. Cryo Lett. 7, 170-183.

Goto, K., Kajihara, Y., Kosaka, S., Koba, M., Nakanishi, Y. \& Ogawa, K. (1988) Pregnancies after co-culture of cumulus cells with bovine embryos derived from in-vitro fertilization of in-vitro matured follicular oocytes. J. Reprod. Fert. 83, 753-758.

Johnson, M.H. \& Pickering, S.J. (1987) The effect of dimethyl sulphoxide on the microtubular system of the mouse oocyte. Development 100, 313-324.

Magistrini, M. \& Szollosi, D. (1980) Effects of cold and of isopropyl-N-phenyl carbamate on the second meiotic spindle of mouse oocytes. Eur. J. Cell Biol. 22, 699-707.

Mobraaten, L.E. (1986) Mouse embryo cryobanking. $J$. in vitro Fert. Embryo Transfer 3, 28-32.

Parkening, T.A. \& Chang, M.C. (1977) Effects of cooling rates and maturity of the animal on recovery and fertilization of frozen-thawed rodent eggs. Biol. Reprod. 17, 527-531.

Pease, A., Schroeder, A.C. \& Schmidt, G.H. (1989) Production of transgenic mice: acupuncture needlefacilitated embryo transfer to oviduct ampulla. Trends Genet. 5, 293.
Pellicer, A., Lightman, A., Parmer, T.G., Behrman, H.R. \& De Cherney, A.H. (1988) Morphologic and functional studies of immature rat oocyte-cumulus complexes after cryopreservation. Fert. Steril. 50, 805-810.

Pickering, S.J. \& Johnson, M.H. (1987) The influence of cooling on the organization of the meiotic spindle of the mouse oocyte. Hum. Reprod. 2, 207-216.

Pincus, G. \& Enzmann, E.V. (1935) The comparative behavior of mammalian eggs in vivo and in vitro. I. The activation of ovarian eggs. J. exp. Med. 62, 655-675.

Sathananthan, A.H., Ng, S.C., Trounson, A.O., Bongso, A., Ratnam, S.S., Ho, J., Mok, H. \& Lee, M.N. (1988) The effects of ultrarapid freezing on meiotic and mitotic spindles of mouse oocytes and embryos. Gamete Res. 21, 385-401.

Schroeder, A.C. \& Eppig, J.J. (1984) The developmental capacity of mouse oocytes that matured spontaneously in vitro is normal. Devl Biol. 102, 493-497.

Schroeder, A.C. \& Eppig, J.J. (1989) Developmental capacity of mouse oocytes that undergo maturation in vitro: effect of the hormonal state of the oocyte donor. Gamete Res. 24, 81-92.

Shalgi, R., Dekel, N. \& Kraicer, P.F. (1979) The effect of LH on the fertilizability and developmental capacity of rat oocytes matured in vitro. J. Reprod. Fert. 55, 429-435.

Sirard, M.A., Parish, J.J., Ware, C.B., LeibfriedRutledge, M.L. \& First, N.L. (1988) The culture of bovine oocytes to obtain developmentally competent embryos. Biol. Reprod. 39, 546-552.

Staigmiller, R.B. \& Moor, R.M. (1984) Effect of follicle cells on the maturation and developmental competence of ovine oocytes matured outside the follicle. Gamete Res. 9, 221-229.

Tsunoda, Y., Parkening, T.A. \& Chang, M.C. (1976) Invitro fertilization of mouse and hamster eggs after deep freezing. J. Reprod. Fert. 50, 123-124.

Van Blerkom, J. \& McGaughey, R.W. (1978) Molecular differentiation of the rabbit ovum. I. During oocyte maturation in vivo and in vitro. Devl Biol. 63, $139-150$.

Van Blerkom, J. \& Runner, M.N. (1984) Mitochondrial reorganization during resumption of arrested meiosis in the mouse oocyte. Am. J. Anat. 171, 335-355.

Vanderhyden, B.T. \& Armstrong, D.T. (1989) Role of cumulus cells and serum on the in vitro maturation, fertilization, and subsequent development of rat oocytes. Biol. Reprod. 40, 720-728.

Wassarman, P.M. \& Fujiwara, K. (1978) Immunofluorescent antitubulin staining of spindles during meiotic maturation of mouse oocytes in vitro. J. Cell Sci. 29, 171-178. 
Whitten, W.K. (1971) Nutrient requirements for culture of preimplantation embryos in vitro. Adv. Biosci. 6, 129-139.

Whittingham, D.G. (1974) Embryo banks in the future of developmental genetics. Genetics, Princeton 78, $395-402$.

Whittingham, D.G. (1977) Fertilization in vitro and development to term of unfertilized mouse oocytes previously stored at $-196^{\circ} \mathrm{C}$. J. Reprod. Fert. 49, 89-94.

Whittingham, D.G., Leibo, S.P. \& Mazur, P. (1972) Survival of mouse embryos frozen to $-196^{\circ} \mathrm{C}$ and $-269^{\circ} \mathrm{C}$. Science, $N Y 178,411$.

Received 8 June 1989 